\title{
VIRALIZANDO O SISTEMA: O MOVIMENTO GAY SHAME E AS SUBVERSÕES ANARQUISTAS
}

\section{VIRILIZING THE SYSTEM: THE GAY SHAME MOVEMENT AND THE ANARCHIST SUBVERSIONS}

\author{
Alcidesio Oliveira da Silva Junior ${ }^{1}$ \\ 1 Universidade Federal da Paraíba, Programa de Pós-Graduação em Educação, Brasil, e-mail: \\ ateneu7@gmail.com, ORCID: https://orcid.org/0000-0002-5536-064X
}

ARTICLE INFO

Article history:

Received 2020-05-28

Accepted 2020-11-30

Available online 2020-11-30
Palavras-chave: Estudos de Gênero. Teoria Queer. Estudos Culturais. Anarquismo Queer. Sexualidade.

Keywords: Gender Studies. Queer Theory. Cultural Studies. Queer Anarchism. Sexuality.

RESUMO. Como um vírus no sistema, infectando as estruturas do capitalismo e dos padrões heterossexuais de se viver/existir, assim surge o Gay Shame, movimento anarquista queer norte-americano sustentado pelos princípios clássicos da cooperação, autogestão e oposição ao Estado. Neste texto, busco tecer entrelaçamentos ousados entre a ação direta extravaganza do movimento e agenciamentos de uma educação anarquista, selvagem, subversiva e perigosamente antenada com as demandas políticas e sociais que emergem por meio da comunidade dos corpos abjetos. Para tanto, envolto nas reflexões pósestruturalistas de Gênero, Sexualidade e do Anarquismo Queer, lanço meus olhares enviesados aos objetivos do Gay Shame e a sua intervenção na 27ª Dyke March realizada em São Francisco/EUA, percebendo que as práticas anarquistas do movimento ao provocarem dissidências e fissuras neste sistema agem como vírus corroendo a imunidade do Capital, na tentativa de enfraquecê-lo cotidianamente por meio de microações políticas nas relações de força a qual estamos inseridxs.

ABSTRACT. Like a virus in the system, infecting the structures of capitalism and heterosexual patterns of living / existing, thus emerges Gay Shame, an American queer anarchist movement supported by the classic principles of cooperation, self-management and opposition to the state. In this text, I seek to weave bold interweavings between the direct extravaganza of the movement and the assemblages of an anarchist, savage, subversive and dangerously attuned to the political and social demands that emerge through the community of abject bodies. Therefore, wrapped in post-structuralist reflections on Gender, Sexuality and Queer Anarchism, I cast my eyes biased towards Gay Shame's objectives and his intervention at the 27th Dyke March held in San Francisco / USA, realizing that the anarchist practices of the movement to the provoking dissidents and fissures in this system act like viruses eroding Capital's immunity, in an attempt to weaken it daily through political microactions in the power relations to which we are inserted.

\section{Introdução}

Um vírus no sistema ${ }^{1}$, destruindo dados lucrativos que sustentam o capitalismo, infectando as estruturas da normatividade sexual e de gênero, disseminando contrariedades e incômodos entre aquelxs que caminham nas zonas confortáveis das hegemonias. Como

\footnotetext{
${ }^{1}$ Tradução minha para A VIRUS IN THE SYSTEM, slogan do movimento Gay Shame presente em suas redes sociais.
} 
se riscasse uma parede de vidro e habitasse entre as fendas, o movimento Gay Shame surge em junho de 1998 na cidade de Nova York/EUA nos anseios libertários, autogestionados e cooperativos de uma proposta anarco-queer, visando combater a supremacia branca, o capitalismo, o poder, a polícia, o colonialismo e todas as formas de dominação².

Em meio a um conservadorismo extremamente aliançado à brutalidade policial, à política de gentrificação de Rudolph Giuliani, Prefeito de Nova York (1994-2002), à demolição de jardins comunitários em função da construção de moradias de luxo, ao policiamento dos espaços sexuais públicos e privados, ao fechamento de sex shops na cidade e à prisão em massa de profissionais do sexo (SYCAMORE, 2008), a "Vergonha Gay" (tradução de Gay Shame) emerge como uma alternativa radical a estas políticas reacionárias, inclusive, apoiadas por proprietárixs de lugares gays, carregadxs de assepsia e desejosxs por transformar a cidade de Nova York em um lugar mais apropriado para xs turistas, afastando, portanto, todxs xs sujeitxs indesejadxs, sujxs, inadequadxs, que historicamente ocupavam os espaços com arte, desejos e sexo.

O Gay Shame avança sobre o legado deixado pós-eclosão dos Novos Movimentos Sociais na década de 1960, que romperam com o centralismo economicista da esquerda tradicional, costurada em torno das teorias marxistas, e trouxeram para a cena política as contestações e lutas do movimento pelos direitos civis da população negra, do movimento feminista da segunda onda e do movimento, então chamado, homossexual (MISKOLCI, 2017). Mas apenas na segunda metade da década de 1980, com a produção dos pânicos sexuais pela epidemia da AIDS, que a Teoria Queer evidencia-se, chamando à luta política/teórica aquelxs sujeitxs que não correspondiam ao padrão do movimento homossexual desta época - branco, classe média e ávido pela incorporação aos modelos sociais heteronormativos/binários - focando, nas suas demandas e organização política, "na crítica às exigências sociais, aos valores, às convenções culturais como forças autoritárias e preconceituosas" (Idem., 2017, p. 25).

Neste texto, busco tecer entrelaçamentos ousados entre a ação direta extravaganza do movimento, termo utilizado por Mattilda Sycamore, umx dxs militantxs do Gay Shame, e agenciamentos de uma educação anarquista, selvagem, subversiva e perigosamente antenada com as demandas políticas e sociais que emergem por meio da comunidade dos corpos abjetos. De que forma as práticas culturais do movimento Gay Shame desembocam em pedagogias culturais na constituição de subjetividades ameaçadoras ao sistema cisnormativo-branco-cristão-classe-média? Para tanto, me aproprio sem nenhum

\footnotetext{
2 "We work collectively outside boring and deceptive non-profit models to fight white supremacy, capitalism, ableism, cops, settler-colonialism and all forms of domination." Disponível em: https://gayshame.net/. Acesso em 25 jul 2019.
} 
compromisso racionalista e generalista, das reflexões dos Estudos de Gênero e Sexualidade, do pensamento Anarquista e do amplo campo dos Estudos Culturais.

Visando os limites deste texto, lanço meus olhares enviesados aos objetivos do Gay Shame e a sua intervenção na $27^{a}$ Dyke March $^{3}$ realizada em São Francisco/EUA no dia 29 de junho de 2019, evento consagrado no calendário queer da cidade e que reúne, segundo o site do evento ${ }^{4}$, todas aquelas mulheres/sapatonas que questionam e desafiam as construções de gênero, bem como as definições sociais das mulheres: trans-sapatonas, male to femme (MTF), transfemininas, transmasculinas, genderqueer e sapatonas fluídas no gênero.

\section{Metodologia}

Para as reflexões aqui propostas, lanço mão da análise cultural com base nos Estudos Culturais, Estudos de Gênero e Sexualidade, em suas transas com as reflexões anarquistas, especialmente na perspectiva pós-estruturalista do anarquismo, inspirada na filosofia de autores como Foucault e Deleuze. Como pesquisa qualitativa, me insiro em um paradigma pós-crítico, compreendendo o gênero e a sexualidade como fabricações atravessadas por discursos (BUTLER, 2018) e produto de arranjos históricos e culturais que materializam as relações de poder aí inscritas (LOURO, 1997).

Para a coleta dos dados, lanço-me a uma pesquisa documental em textos e materiais

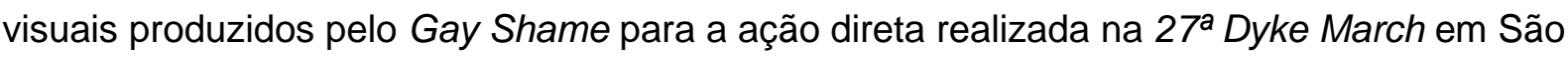
Francisco, "investigando, examinando, usando técnicas apropriadas para seu manuseio e análise" (SÁ-SILVA et al., 2009, p. 4). Me revestindo das possibilidades de escrita que o pós-estruturalismo me permite, resolvo aqui compor um texto onde as costuras teóricas e as argumentações analíticas formem um só tecido, evitando, por escolha política e estética, as divisõés de um artigo convencional.

\section{A ação direta EXTRAVAGANZA}

Emergindo em um contexto político de acirramento do conservadorismo em Nova York em 1998, o Gay Shame espalhou-se como uma epidemia queer em outras cidades dos Estados Unidos, alcançando voos em outros países, como a Suécia em 1998. Em São Francisco, cidade conhecida por sua esfuziante comunidade LGBTQI+, o movimento chega em 2001 animado por Mattilda Sycamore, militante queer, na tentativa de construir espaços onde as práticas de esperança constrastassem com uma realidade de apodrecimento do

\footnotetext{
3 "Marcha das Sapatonas" (Tradução minha). Dyke é uma gíria originalmente tomada como ofensa lesbofóbica, mas recuperada pelxs militantes queer, ressignificando-a.

${ }^{4}$ https://www.thedykemarch.org/dyke-identity. Acesso em 26 jul. 2019.
} 
mundo, inclusive na cultura queer, que, na cidade, havia sido demolida e substituída por "[...] hipsters da alta moda procurando as festas mais bacanas" (SYCAMORE, 2008, p. 239, tradução minha) ${ }^{5}$.

Para Sycamore, naquele lugar de normatização das práticas de gênero e de sexualidade, conduzidas como atos de consumo do capitalismo, o Gay Shame "[...] foi uma oportunidade de ajudar a construir algo transformador, desviante e perigoso fora da alienação e desespero" (2008, p. 239, tradução minha) ${ }^{6}$. Como sabemos, além das lutas de ordem econômica que os grupos mais desfavorecidos empreendem, outras práticas culturais dentro da sociedade hegemonicamente branca, cristã, heterosexual e cisnormativa, sustentadas em binanismo opressor e silenciador, atuam na tentativa de encarcerar as singularidades, encaixotando-as em modelos aceitáveis pela ordem dominante e, como um dos seus braços mais expressivos, pelo Estado.

Estas molduras acabaram sendo abraçadas pelo movimento gay e lésbico tradicional, surgidos na movimentada década de 60 , desejosos por uma aceitação social e por direitos civis conquistados na base da normatividade, da reprodução do modo heterossexual de viver e na discrição, acima de tudo. De acordo com Miskolci (2017, p. 2425):

\begin{abstract}
Em sua maior parte, o movimento homossexual emerge marcado por valores de uma classe-média letrada e branca, ávida por aceitação e até mesmo incorporação social. Algo muito diverso se passa quando surgem movimentos queer, se pautarão menos pela demanta de aceitação ou incorporação coletiva e focarão mais na crítica às exigências sociais, aos valores, às convenções culturais como forças autoritárias e preconceituosas.
\end{abstract}

Assim, o Gay Shame lança-se na empreitada de viralizar o sistema em diversos pontos onde pode alcançar por meio da internet e de sua militância. Mas que sistema estamos falando? Justamente aquele denunciado pela Teoria Queer e baseado na rejeição de todos os corpos que não condizem com os modelos esperados-desejados-amados pela sociedade heteronormativa, branca e cristã: "[...] aqueles e aquelas considerados anormais ou estranhos por deslocarem o gênero ou não enquadrarem suas vidas amorosas e sexuais no modelo heteroreprodutivo" (MISKOLCI, 2017, p. 25).

Dentre as várias ações implementadas pelo Gay Shame - além dos encontros regulares divulgados no site e que promovem performances, formações políticas, venda de comida vegana e expressões culturais variadas na música e na dança - vemos movimentações contra a especulação imobiliária que afeta a população de baixa renda, contra o avanço do conservadorismo e o fascismo na política, contra o Estado e contra as

\footnotetext{
5 "[...] high-fashion hipsters looking for the coolest parties".

6 "[...] has been an opportunity to help build something transformative, deviant, and dangerous out of alienation and desperation".
} 
práticas opressoras aos corpos abjetos da sociedade. Incorporando práticas do movimento anarquista, como a ação direta e propaganda revolucionária, o Gay Shame advoga a emergência de uma cultura de resistência a toda forma de dominação, inclusive na comunidade LGBTQI+, munida, muitas vezes, de uma ideia de construção de Estado por meio da determinação de políticas vindas de cima. Porém, “[...] uma posição anarquista pósestruturalista sugere que o Estado não determina políticas, mas que certas práticas políticas (incluindo, mas não só, eleições e lobby) produzem o Estado (HECKERT, 2015, p. 178, grifo do autor).

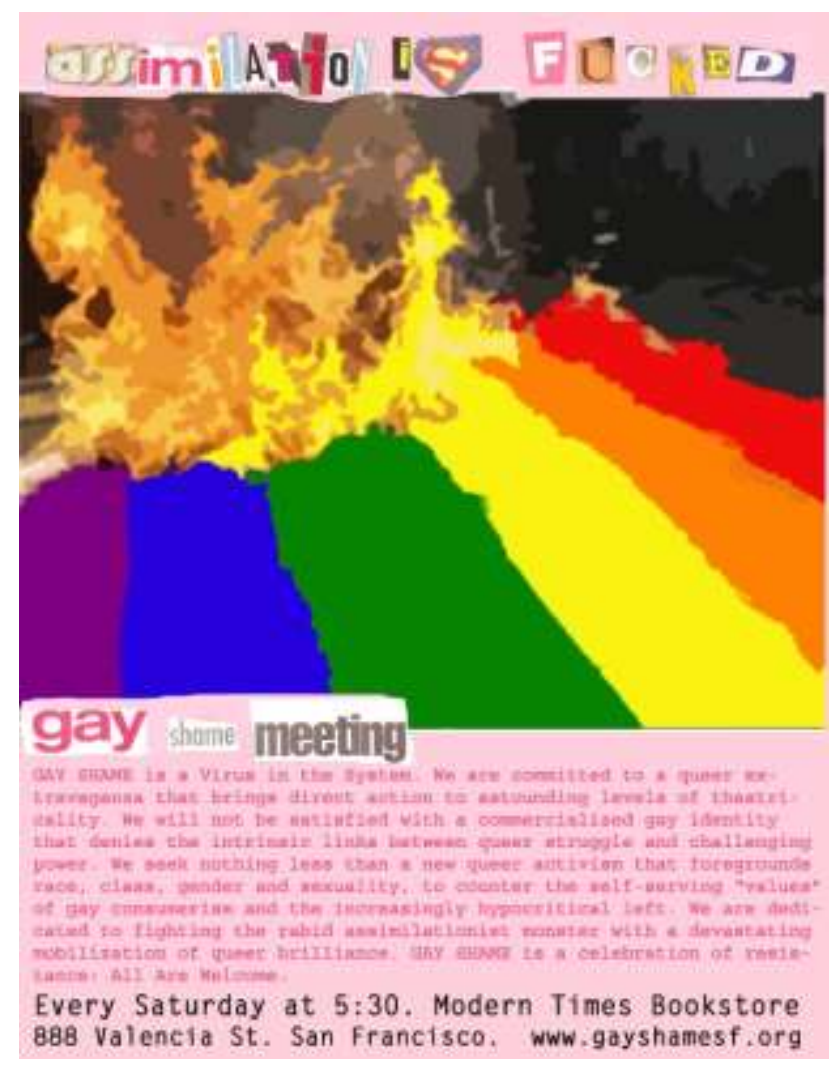

Figura 1 - Divulgação dos encontros do Gay Shame em São Francisco

Fonte: Site oficial do movimento ${ }^{7}$

Assim, são as práticas cotidianas levadas a sério pelo movimento, bem como a construção de uma cultura de cooperação e solidariedade, distantes do ideal capitalista sustentado pelo individualismo liberal e a competição, que promovem fissuras no sistema de dominação - seja de gênero, classe, sexual, racial ou étnico -, colaborando para um mundo mais justo e sem amarras. O teor da propaganda e da formação política, construídas nas microrelações e nas intervenções locais pelo movimento, podem ser evidenciadas na materialização discursiva de sua práxis política, como também nos materiais disponíveis no site para download e compartilhamento livre. O primeiro zine distribuído gratuitamente pelo movimento, por exemplo, entitulado Swallow Your Pride: A Do-It-Yourself Guide to Hands-

\footnotetext{
${ }^{7}$ Disponível em: https://gayshame.net/wp-content/uploads/2017/11/burning-rainbow-flag.jpg. Acesso em 27 jul 2019.
} 
On Activism (Engula o seu orgulho: Um guia "faça você mesmo" para um ativismo prático tradução minha) contém dicas de grafitagem, formas de desobedicência civil, artigos sobre oficinas clandestinas e organizações sindicais, sobre a repressão ao sexo público, ativismo gordo e informações sobre troca de seringas e AIDS (SYCAMORE, 2008).

Mais do que um movimento por uma sexualidade libertária, o Gay Shame levanta a bandeira de todxs xs sujeitxs oprimidxs nesta sociedade injusta e desigual. Faço coro as palavras de Miskolci ao argumentar que "[...] um olhar queer é um olhar insubordinado. É uma perspectiva menos afeita ao poder, ao dominante, ao hegemônico, e mais comprometida com os sem poder, dominados, ou melhor, subalternizados" (2018, p. 48).

\subsection{Contra todo o autoritarismo - POLÍCIAS, FORA!}

Como ataque ao autoritarismo e policiamento das sexualidades, trago para este texto a ação direta realizada na $27^{a}$ Dyke March em São Francisco/EUA no dia 29 de junho de 2019, evento anual que reúne a militância sapatona (tradução para Dyke) feminista/transfeminista na luta por mais visibilidade, espaços políticos, direitos e respeito. Reconhecendo o histórico de opressão e de violência exercidos pela polícia, braço armado do Estado, o Gay Shame realizou uma propaganda prévia e intervenção durante o evento pela não presença dos policiais na Dyke March.

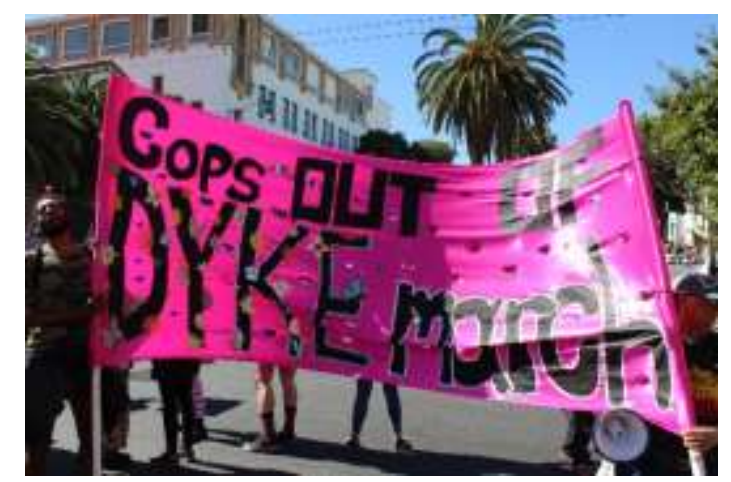

Figura 2 - Intervenção na Dyke March 2019

Fonte: Site oficial do movimento ${ }^{8}$

A manifestação chamada Cops out of Dyke March (Policiais fora da Marcha das Sapatonas, tradução minha) tinha o caráter de denunciar as práticas de violência do Estado à comunidade LGBTQI+, especialmente àquelxs que fogem da normatividade heterossexual, estética e de relacionamento amoroso/sexual, xs principais alvxs das políticas de silenciamento e violência simbólica, ou até mesmo física, deste grupo. Um dos

${ }^{8}$ Disponível em: https://gayshame.net/wp-content/uploads/2019/06/IMG_0741.jpg. Acesso em 27 jul 2019. 
cartazes (Figura 3) chama as pessoas para a Marcha, porém destaca que Cops are NOT DYKES, Cops are...(Policiais NÃO SÃO SAPATONAS, Policiais são..., tradução minha) enumerando uma série de práticas cotidianas sofridas pela população queer.

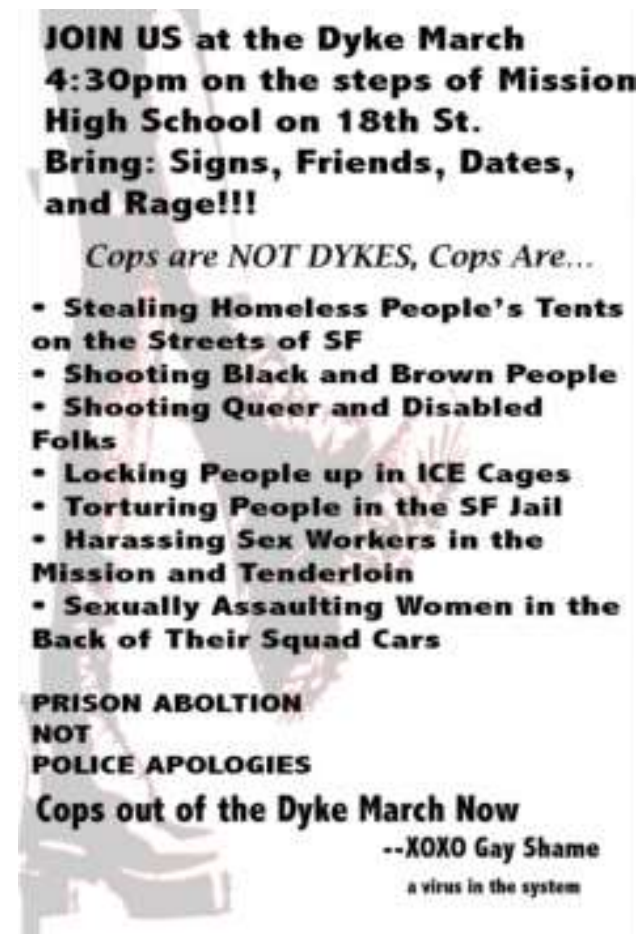

Figura 3 - Cartaz "Cops are not dykes, Cops are..."

Fonte: Site oficial do movimento ${ }^{9}$

Aqui faço uso da conceituação mais ampla do movimento queer, em especial do anarquismo queer, que constrói as suas lutas em favor dos abjetos da sociedade, das pessoas marginalizadas, excluídas, dignas de nojo, repulsa, cuja existência é um ataque ao sistema. De acordo com Miskolci (2017, p. 24), a abjeção “[...] se refere ao espaço em que a coletividade costuma relegar aqueles e aquelas que considera uma ameaça ao seu bom funcionamento, à ordem social e política." Desta forma, ao trazer para o foco da luta e da denúncia não apenas questões que dizem respeito às opressões de gênero e de sexualidade, o Gay Shame ergue uma bandeira do anarquismo tradicional e que persiste em suas correntes contemporâneas. Vemos na Figura 3 a denúncia da opressão policial às pessoas sem teto, o assassinato do povo negro, as torturas nas prisões de São Francisco, o assédio às/aos/xs profissionais de sexo, as agressões sexuais cometidas nos próprios carros das corporações, entre outras injúrias.

O que estas pedagogias culturais podem ensinar? Que singularidades carregadas de rebeldias podem aflorar? Tomo o conceito de pedagogia cultural dos Estudos Culturais, compreendendo que "[...] a educação como vontade de governar, de moldar e dirigir

${ }^{9}$ Disponível em: https://gayshame.net/index.php/cops-out-of-dyke-march-2019/. Acesso em 27 jul 2019. 
condutas [...] são praticadas em distintos espaços e contextos" (COSTA; ANDRADE, 2015, p. 845). O Gay Shame, e seu anarquismo queer, além de posicionar-se nas disputas em torno de narrativas, na educação mútua e como propositor de espaços outros anti-hierarquia e antiautoritarismo, confunde, viraliza, infecta o sistema em função da evidenciação de outras formas de pensar, transar, amar, ser...

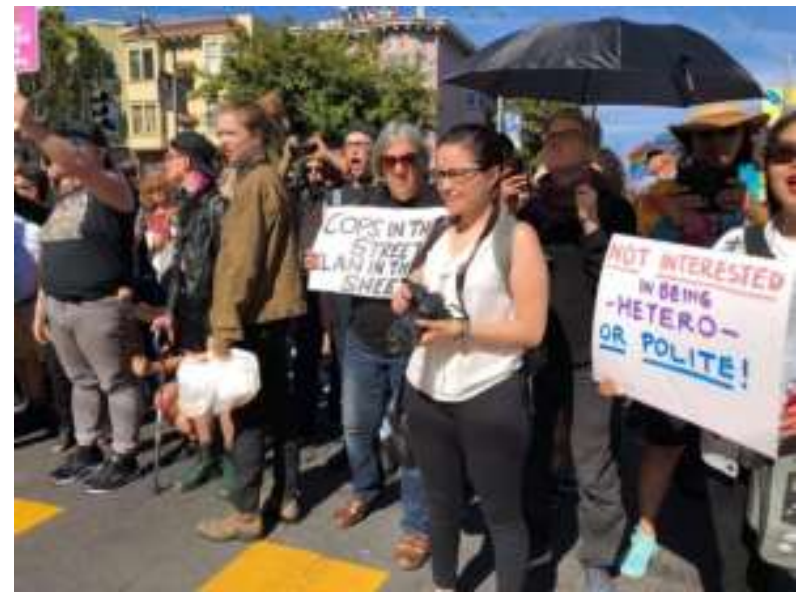

Figura 4 - Manifestação do Gay Shame em São Francisco

Fonte: Site oficial do movimento ${ }^{10}$

Ao se posicionar contra uma sociedade heteronormativa, que inclusive interpela os sujeitos LGBTQI+'s, e contra uma sociedade capitalista, o anarquismo queer estilhaça vidros de caixas sólidas, porém históricas e culturais, que prendem a criatividade e as diferenças. Ao trazer para a cena que tais elementos são produtos históricos e vontades de verdade, e que podem ser questionados, revistos, transformados, o Gay Shame problematiza a construção desta realidade opressora, visando novos caminhos possíveis, pois "[...] é preciso ter em mente que hierarquias não são espaços de controle perfeito, as brechas autônomas fissuram e rompem a solidez da estrutura hierárquica" (GARCIA, 2012, p. 330).

\section{Considerações finais}

Nestas linhas intencionei causar reflexões em torno do movimento queer, reforçando o seu conceito rebelde em torno das lutas que, de fato, evidenciam as desigualdades sociais, de gênero, econômicas, raciais e étnicas que permeiam a atual sociedade. $O$ capitalismo, pensamento basilar da contemporaneidade e que entrecorta praticamente todas as relações sociais que vivenciamos, não é um sistema intransponível e as movimentações anarquistas de grupos como Gay Shame ao provocarem dissidências e fissuras neste

\footnotetext{
${ }^{10}$ Disponível em: https://gayshame.net/index.php/cops-out-of-dyke-march-2019/. Acesso em 27 jul 2019.
} 
sistema agem como vírus corroendo a imunidade do Capital, na tentativa de enfraquecê-lo cotidianamente por meio de microações políticas nas relações de força a qual estamos inseridxs.

Dessa forma, ao continuar erguendo as bandeiras de justiça social e equidade econônica levantadas pelos movimentos anarquistas tradicionais, o anarquismo queer agrega como foco de sua luta também outras formas de opressão e de autoritarismo, como a hierarquia de gênero e da sexualidade. Vê-las como dispositivos de regulação/controle, como bem argumenta Foucault $(1998,2014)$, evidencia os entrelaçamentos dos grupos hegemônicos para se manterem no regimento dos comportamentos aceitáveis e nas formas "adequadas" de se viver. O Anarquismo vive e trans-põe cadeias!

\section{Referências}

BUTLER, Judith. Problemas de gênero: Feminismo e subversão da identidade. Tradução de Renato Aguiar. 16. ed. Rio de Janeiro: Civilização Brasileira, 2018.

COSTA, Marisa Vorraber; ANDRADE, Paula Deporte de. Na produtiva confluência entre educação e comunicação as pedagogias culturais contemporâneas. PERSPECTIVA, Florianópolis, v. 33, n. 2, p. 843-862, maio/ago., 2015.

FOUCAULT, Michel. História da sexualidade I: A vontade de saber. Tradução de Maria Thereza da Costa Albuquerque e J. A. Guilhon Albuquerque. 19 ed. Rio de Janeiro: Edições Graal, 1998. v. 1.

FOUCAULT, Michel. Vigiar e punir: nascimento da prisão. Tradução de Raquel Ramalhete. 42 ed. Petrópolis, RJ: Vozes, 2014.

GARCIA, Loreley Gomes. Sexo e anarquia: uma combinação explosiva. Estudos Feministas, v. 20, n. 01, p. 327-330, 2012.

HECKERT, Jamie. Anarquismo e sexualidade: rumo a relações consensuais. Verve, n. 28, p. 169-195, 2015.

LOURO, Guacira Lopes. Gênero, sexualidade e educação: uma perspectiva pósestruturalista. Petrópolis, RJ: Vozes, 1997.

MISKOLCI, Richard. Teoria Queer: um aprendizado pelas diferenças. 3. ed. rev. e ampl. Belo Horizonte: Autêntica Editora, Universidade Federal de Ouro Preto, 2017 (Série Cadernos da Diversidade; 6).

SÁ-SILVA, Jackson Ronie et al. Pesquisa documental: pistas teóricas e metodológica. Revista Brasileira de História \& Ciências Sociais, v. 1, n. 1, p. 01-15, 2009.

SYCAMORE, Mattilda Bernstein. Gay Shame: from queer autonomous space to direct action extravaganza. In: (Org.). That's revolting!: Queer strategies for resisting assimilation. Brooklyn: Soft Skull Press, 2008, p. 237-262. 